\title{
UM OLHAR SOBRE AS POLÍTICAS PÚBLICAS DA EDUCAÇÃO DO CAMPO E EDUCAÇÃO ESPECIAL À LUZ DA PEDAGOGIA HISTÓRICO-CRÍTICA
}

\author{
A look at the public policies of Rural Education and Special Education in the \\ light of historical-critical pedagogy
}

\author{
Una mirada sobre las políticas públicas de la Educación Del Campo y la \\ Educación Especial a la luz de la pedagogía histórico-crítica
}

\author{
Jackeline Silva Alves* \\ Arlindo Lins de Melo Júnior** \\ Kátia Regina Moreno Caiado ${ }^{* * *}$
}

\begin{abstract}
Resumo
Nesse ensaio busca-se tecer um olhar sobre as políticas educacionais orientadas para o atendimento da educação do campo e da educação especial, objetivando identificar e discutir as interfaces encontradas na legislação que trata sobre tais modalidades de ensino. A orientação teórico-metodológica utilizada para tal construção teórica está ancorada no Materialismo Histórico Dialético e nos referenciais pedagógicos da Pedagogia Histórico-Crítica. A partir das observações realizadas junto às Leis, Decretos, Normas e Resoluções que versam sobre a Educação em si, e sobre as modalidades Educação do campo e Educação Especial, constata-se que ocorreram avanços no ordenamento jurídico que disciplina o tema, todavia, muitas ainda são as lacunas existentes sobre a produção do conhecimento no que tange à aplicação prática de tais normas. Os resultados demonstram haver, nas políticas públicas da educação do campo e educação especial, uma interface encontrada que remete ao direito dos estudantes do campo com deficiência de serem escolarizados no lugar onde residem.
\end{abstract}

PALAVRAS-CHAVE: Política Educacional. Educação do Campo. Educação Especial

\begin{abstract}
This essay seeks to look at the educational policies aimed at attending the education of the field and special education, aiming to identify and discuss the interfaces found in the legislation that deals with such modalities of teaching. The theoretical-methodological orientation used for this theoretical construction is anchored in the Historical Materialism Dialectic and in the pedagogical references of Historical-Critical Pedagogy. Based on the observations made with the Laws, Decrees, Norms and Resolutions that deal with Education itself, and on the modalities Education of the field and Special Education, it is noted that there have been advances in the juridical order that disciplines the subject, however, many there are still gaps in the production of knowledge with regard to the practical application of such standards. The results show that there is an interface found in the public policies of

\footnotetext{
* Doutoranda em Educação pelo Programa de Pesquisa e Pós-graduação da Universidade Federal de São Carlos. Docente do ensino superior no Curso de Geografia da Universidade Estadual de Goiás. E-mail: jackgeo17@gmail.com mail: arlindoef@hotmail.com

*** Graduada em Pedagogia pela Pontifícia Universidade Católica de Campinas. Mestre em Educação Especial pela Universidade Federal de São Carlos e Doutora em Educação pela Universidade de São Paulo. Professora adjunta no Centro de Educação e Ciências Humanas, na Universidade Federal de São Carlos. Docente no Programa de Pós-Graduação em Educação Especial. E-mail:caiado.katia@gmail.com
}

${ }_{* *}^{*}$ Mestrando em Educação pela Universidade Federal de São Carlos - campus - Sorocaba. Bolsista CAPES. E-
\end{abstract}


rural education and special education, which refers to the right of rural students with disabilities to be educated in the place where they live.

KEYWORDS: Education Policy. Rural Education. Special Education

\section{Resumen}

En este ensayo se busca hacer una mirada sobre las políticas educativas orientadas a la atención de la educación del campo y de la educación especial, con el objetivo de identificar y discutir las interfaces encontradas en la legislación que trata sobre tales modalidades de enseñanza. La orientación teóricometodológica utilizada para tal construcción teórica está anclada en el Materialismo Histórico Dialéctico y en los referenciales pedagógicos de la Pedagogía Histórico-Crítica. A partir de las observaciones realizadas en las Leyes, Decretos, Normas y Resoluciones que versan sobre la Educación en sí, y sobre las modalidades Educación del campo y Educación Especial, se constata que ocurrieron avances en el ordenamiento jurídico que disciplina el tema, sin embargo, muchas todavía son las lagunas existentes sobre la producción del conocimiento en lo que se refiere a la aplicación práctica de dichas normas. Los resultados demuestran haber, en las políticas públicas de educación del campo y educación especial, una interfaz encontrada que remite al derecho de los estudiantes del campo con discapacidad de ser escolarizados en el lugar donde residen.

PALABRAS CLAVE: Política Educativa. Educación del Campo. Educación Especial

\section{INTRODUÇÃO}

O sistema educacional brasileiro se realiza por meio de sistemas de ensino, envolvendo as esferas da União, dos Estados, do Distrito Federal e dos Municípios. A atual organização do sistema de ensino regular está estruturada em níveis, abrangendo a Educação Básica e a Educação Superior.

A Educação Básica é estruturada por fases/etapas, que compreende a Educação Infantil (creche e pré-escola), ao Ensino Fundamental (Anos iniciais e Anos Finais) e o Ensino Médio. Esta última é a etapa que finaliza a Educação Básica, com duração mínima de três anos, a qual oferece uma formação geral aos estudantes. Nesta fase, é permitido pela legislação educacional a inclusão de programas de preparação geral para o trabalho, sendo opcional ao estudante a escolha da habilitação profissional (BRASIL, 1996). Ademais, a educação escolar possui modalidades específicas de ensino, sendo elas: Educação de Jovens e Adultos, Educação Especial, Educação Profissional e Tecnológica, Educação do Campo, Educação Escolar Indígena, Educação Escolar Quilombola e Educação à Distância.

$\mathrm{Na}$ educação escolar é possível evidenciar o movimento entre duas subáreas de conhecimento: a Educação do Campo e a Educação Especial, no sentido de garantir uma escolarização básica que "leve em conta as características de quem vive no campo e também das pessoas que apresentam deficiências, transtornos globais do desenvolvimento e altas habilidades/superdotação" (ANJOS, 2016, p. 15).

Pensar sobre a interface entre educação do campo e educação especial instiga um olhar sobre o sistema educacional brasileiro e, consequentemente, sobre as determinações legais e normativas encontradas nas políticas educacionais que permeiam essas duas modalidades de ensino pertencentes à grande área da Educação. Tal consideração se torna ainda mais relevante ao considerar o fato de que os alunos com deficiência ${ }^{1}$ que estudam em escolas localizadas na zona rural $^{2}$ têm o direito de acesso e permanecia ao sistema escolar onde estão alocados.

\footnotetext{
${ }^{1}$ Dentro das deficiências podemos citar: intelectual, física, visual, auditiva, múltipla, surdocegueira.

${ }^{2}$ Cabe ressaltar que as escolas situadas na área rural são denominadas de escolas do campo (BRASIL, 2010).
} 
Sendo assim, a educação escolar básica brasileira tem sido objeto de contradições entre aquilo que se considera fundamental para o processo de transformação e emancipação social, e sua efetivação prática, haja vista os antagonismos que sempre permearam os interesses hegemônicos que fundamentam a atuação do Estado brasileiro na elaboração de Políticas e dos programas educacionais (BEZERRA NETO; BEZERRA; CAIADO, 2011).

Neste sentido, o direito à escola, o qual compreende matrícula, permanência, apropriação do conhecimento para a participação social e o respeito às especificidades das pessoas com deficiência, bem como suas peculiaridades culturais e sociais da vida no campo, deve ser constantemente observado e reivindicado pela sociedade, visando um empoderamento efetivo destas políticas (CAIADO; MELETTI, 2011).

A Lei de Diretrizes e Bases da Educação Nacional - LDB (Lei 9394/96) afirma a garantia da entrada e a permanência do aluno com deficiência no ambiente da escola regular, quer seja este da zona urbana ou rural. Dessa maneira, a educação do estudante com deficiência filho do trabalhador rural, assim como a educação efetivamente destinada aos residentes do campo, têm acompanhado essa discussão, não só por parte do poder público, mas também, dos movimentos sociais.

Estudos realizados na área da educação demonstram existir um quantitativo importante de alunos com deficiência matriculado em escolas do campo, sendo, desta forma, relevante a realização de pesquisas que trabalhem a interface entre as modalidades educação do campo e educação especial no âmbito da academia (CAIADO; MELETTI, 2011; LOUREIRO; SÁ; SELINGARDI, 2011; JESUS; ANJOS, 2012; GONÇALVES, 2014; PASTORIZA, 2015).

Para este estudo, foi utilizado o ensaio científico, Severino (2011) discorre que tal estratégia metodológica é um estudo bem desenvolvido, formal, discursivo e concludente que consiste na exposição lógica e reflexiva e em argumentação rigorosa, com alto nível de interpretação e julgamento do autor; no ensaio, este tem maior liberdade para defender determinada posição, utilizando uma problematização e um objetivo para melhor delimitação textual. Ademais, serve-se de documentação empírica e bibliográfica, recursos estes também utilizados em outros tipos de trabalhos científicos das Ciências Humanas e, consequentemente, educacionais.

Este ensaio científico tem como objetivo identificar e discutir as interfaces encontradas entre a educação do campo e educação especial, destacando aspectos destas interseções para a escolarização dos alunos com deficiência residentes no campo apontadas nas principais políticas educacionais (BRASIL, 2001; 2008a; 2008b; 2010; 2011; 2012; 2015) da educação do campo e da educação especial, à luz do Materialismo Histórico-Dialético (MHD), discorridos na Pedagogia Histórico-Crítica (PHC).

No processo investigativo para a produção deste ensaio científico, despontou-se como problema central a seguinte pergunta: O que as políticas educacionais da educação do campo e da educação especial, em sua interface, trazem em benefício dos alunos com deficiência residentes no campo?

\section{Discussão}

\section{Princípios norteadores encontrados nas políticas educacionais que trazem a interface entre educação do campo e educação especial}


A Educação constitui-se como um direito social fundamental e os princípios norteadores da mesma estão expressos na Constituição Federal Brasileira de 1988 e na LDB (Lei 9394/96) - principal lei da educação nacional e complementar à Constituição Federal.

Conforme expresso no Capítulo II da Constituição Federal Brasileira (1988), no Artigo 205, a "educação, direito de todos e dever do Estado e da família, será promovida e incentivada com a colaboração da sociedade, visando ao pleno desenvolvimento da pessoa, seu preparo para o exercício da cidadania e sua qualificação para o trabalho" (BRASIL, 1988, p. 136).

Nessa mesma direção, a LDB (9394/96), no Título II, que trata Dos Princípios e Fins da Educação Nacional, em seu artigo $2^{\circ}$ diz: "a educação dever da família e do Estado, inspirado nos princípios da liberdade e nos ideais de solidariedade humana, tem por finalidade o pleno desenvolvimento do educando, seu preparo para o exercício da cidadania e sua qualificação para o trabalho" (BRASIL, 2017, p. 8).

A legislação afirma que desenvolvimento escolar dos alunos com ou sem deficiências residentes nas áreas urbanas ou rurais é inerente ao exercício da cidadania. Assim, por meio da educação (escolarização), estes alunos serão capazes de realizar seu trabalho intelectual ou físico. No Artigo $3^{\circ}$ da LDB (9394/96) estão postos os princípios que devem orientar a educação nacional e, merecendo destaque pelos debates acadêmicos e políticos que podem desencadear, ressalta-se os seguintes: (a) Igualdade de condições para o acesso e permanência na escola; (b) Pluralismo de ideias e de concepções pedagógicas; (c) Garantia de padrão de qualidade; (d) Valorização da experiência extraescolar; (e) Vinculação entre educação escolar, o trabalho e as práticas sociais; (f) Consideração com a diversidade étnico-racial.

Se num contexto mais amplo o panorama geral delineado para a educação é marcado por contrassensos, isto fica um tanto mais evidente quando considerados os princípios anteriormente destacados nas modalidades de Educação do campo ${ }^{3}$ na interface com Educação Especial ${ }^{4}$.

Quando se trata sobre a interface encontrada na Educação do campo e Educação Especial, destacamos que, muitas vezes, tais modalidades têm sido investigadas separadamente e a partir de abordagens teórico-metodológicas distintas entre diversos autores que têm pesquisado sobre o assunto. Contudo, destaca-se aqui alguns renomados pesquisadores que lideram Grupos de pesquisa ${ }^{5}$ cadastrados no Conselho Nacional de Desenvolvimento Científico e Tecnológico ( $\mathrm{CNPq}$ ) e que têm buscado, junto aos seus orientandos dos cursos de PósGraduação (Mestrado/Doutorado), realizar investigações mais críticas no viés do materialismo histórico-dialético sobre tais modalidades de ensino, bem como, sobre as interfaces existentes entre elas.

Assim, ao se utilizar os aspectos teóricos-metodológicos do MHD desenvolvidos na PHC para compreender essa interface, toma-se como base pensadores como Lombardi (2011) e Saviani (2013), os quais colocam em relevo a importância de observar a inter-relação entre os aspectos políticos, sociais e trabalhistas acumulados historicamente pela humanidade para compreender a realidade concreta.

Orso (2016) levanta uma crítica contra a defesa dos tipos específicos de educação para grupos ou frações sociais distintas que não se articulam entre si, dentro de uma ou várias modalidades da educação, a fim de compreender este isolamento e a falta de transversalidade

\footnotetext{
${ }^{3}$ A Educação do Campo, trata-se de uma modalidade de ensino que que tem como objetivo a educação de crianças, jovens e adultos que vivem no campo.

${ }_{4}$ Educação Especial, modalidade de ensino ofertada a estudantes com deficiência, transtornos globais de desenvolvimento e altas habilidades ou superdotação.

${ }^{5}$ Dentre os Grupos de Pesquisas citados e registrados junto ao CNPq destacam-se o Núcleo de Estudos e pesquisas em direito à educação - Educação Especial (NEPEDE-EEs), e o Grupo de Estudos e Pesquisas sobre Educação no Campo (GEPEC).
} 
entre as subáreas da educação escolar. Sobre isto, o autor remete ao entendimento que a sociedade educacional possui, a qual, muitas vezes, se resume a paradigmas que não trazem em seu bojo uma análise teórico-metodológica não dialógica, ou seja, que vise entender os conflitos oriundos de uma sociedade dividida em classes. Assim, destaca:

\begin{abstract}
Se a entendermos na perspectiva positivista, estruturalista, fenomenológica e pósmoderna, pode-se se dizer que a sociedade se compõe de um conjunto de segmentos e de elementos articulados ente si, cada um com suas individualidades, suas experiências, suas necessidades e especificidades e que tem direito a um tipo de educação diferente, adequado aos seus gostos e a seus guetos (ORSO, 2016, p. 99).
\end{abstract}

De tais orientações teórico-metodológicas resultam trabalhos que supervalorizam a subjetividade fragmentada e dilacerada, ocultando, por vezes, os reais determinantes das desigualdades sociais, à qual se encontra submetida grande parte da população brasileira. Sendo assim, torna-se necessário questionar tal estrutura social capitalista.

Ainda, é percebido que os alunos no campo com ou sem deficiência (filhos de trabalhadores sem-terra, assentados, caiçaras, ribeirinhos, quilombolas, indígenas e caipiras, dentre outros) os professores, os gestores e toda a comunidade escolar do campo são desprovidos da interface entre a educação do campo e educação especial, discorridas na Constituição da República, na LDBEN e nos dispositivos mais recentes da educação do campo e especial (BRASIL, 2008a; BRASIL, 2008B; BRASIL, 2010; BRASIL, 2012; BRASIL, 2015).

Desta forma, uma vez que os conhecimentos historicamente acumulados pela humanidade são transmitidos aos estudantes do campo com ou sem deficiência, dão-lhe uma força intelectual que os capacitará para a luta por suas atividades culturais e pela de emancipação contra o capitalismo. Assim, é a falta de conhecimento que traz a extinção da cultura ancestral.

Em outras palavras, conforme reforçam Gomes e Colares (2012, p. 282),

[...] o discurso híbrido do 'pós-modernismo' protesta contra as noções clássicas de razão, verdade, objetividade, o conceito de progresso, emancipação universal ou as grandes narrativas. [...]O pensamento pós-moderno significou a consolidação no âmbito da ideologia dos interesses burgueses, na medida em que afirma a impossibilidade do conhecimento objetivo e a superação da ordem social existente, substituindo a luta de classe pela lógica do contentamento das múltiplas identidades que compõe o mosaico social.

Por isso, corroborando das proposições elaboradas por Bezerra e Santos (2017, p. 17), entende-se que

O materialismo histórico parte de uma concepção concreta do mundo, da vida, da
realidade em si e funciona como mediador do processo de entendimento da
estruturação, do desenvolvimento e da transformação dos fenômenos sociais
investigados. Na apreensão de Marx e Engels (2002), o mundo e tudo o que nele está
contido tem existência material, concreta, podendo ser racionalmente conhecidos.
[...]para que isto seja alcançado, é preciso ultrapassar a superficialidade, a aparência
imediata das coisas e atingir a essência. Esta é uma tarefa complexa, pois a realidade
que nos envolve se apresenta como um todo caótico, permitindo, apenas por meio da
abstração, analisar suas partes constituintes.

Ainda, Orso (2016) ressalta que todos os grupos ou frações sociais que se importam apenas com as especificidades culturais necessitam ser educados e, nesse sentido, não se justifica a necessidade de uma educação específica para cada grupo ou frações sociais, como 
tem sido observado no discurso hegemônico do capitalismo. Desta maneira, a escolarização ofertada no meio urbano deveria ser de qualidade e igualmente disponibilizada no campo para os alunos com ou sem deficiência.

Para o autor, tal forma de conceber a educação está relacionada à forma com que compreendemos a sociedade, e a educação no interior desta. Nesse sentido, acrescenta que "se pensarmos numa perspectiva dialética e de totalidade, entenderemos que a sociedade é composta por elementos diferentes, permeada por contradições compondo uma mesma unidade e, portanto, tem o direito de participar dessa universalidade" (ORSO, 2016, p. 99-100).

Com base no exposto, torna-se imperativo desenvolver um entendimento de sociedade e de educação que permita superar a ideia de fragmentação, entendendo as múltiplas identidades que compõe o mosaico social, como união de contrários e síntese de múltiplas determinações (ORSO, 2016).

Saviani (2016) aponta que, para o tão almejado processo de transformação da realidade e, por conseguinte, da sociedade, não podemos perder de vista, no processo educativo, a perspectiva histórica, pois é necessária para a formação de uma consciência crítica a respeito dos condicionantes histórico-sociais que marcam o contexto em que se desenvolve a prática social dos homens do campo no Brasil. Assim, se faz necessária uma reflexão sobre o fato de que o homem do campo e seus filhos não estão livres de nascerem, crescerem ou desenvolverem alguma deficiência e, por isso, cabe ao conjunto (gestão, direção, professores e toda comunidade escolar) estar preparado para receber os alunos com deficiência.

Neste sentido, Saviani (2016) reflete que,

Considerando que as características especificamente humanas não estão inscritas na genética e, portanto, não são herdadas pelos indivíduos ao nascer, mas são produzidas historicamente devendo ser adquiridas por meio da atividade educativa, a pedagogia histórico-crítica define a educação como o ato de produzir, direta e intencionalmente, em cada indivíduo singular a humanidade que é produzida histórica e coletivamente pelo conjunto de homens (SAVIANI, 2016, p. 18).

Desde os tempos mais remotos, o homem precisou se relacionar com a natureza, retirando desta os elementos necessários à satisfação de suas necessidades mais imediatas de sobrevivência, tais como, alimentar-se, vestir, morar, etc. Até então, o ato de se relacionar com a natureza e o ritmo de trabalho e de vida associava-se ao ritmo da natureza.

Entretanto, à medida em que a humanidade foi se desenvolvendo, outras formas de relação entre os homens (organização social), bem como as formas de se relacionar com a natureza, foram sendo estabelecidas. Saviani (2012, p. 21) ressalta que, "a forma básica e primeira de atividade humana é a de transformação da natureza. O produto do trabalho é, ao mesmo tempo, a realização de um objetivo previamente existente na mente humana e a transformação da atividade dos sujeitos em propriedades dos objetos".

Ademais, de acordo com Saviani (2016), na transformação da natureza, por meio do trabalho, o homem se educa, ainda que tal prática não se constitua em educação formal. Ao tratar sobre tal mediação, o autor destaca que:

[...] o homem não nasce homem. Ele se forma homem. Ele não nasce sabendo produzir-se como homem. Ele necessita aprender a ser homem, precisa aprender a produzir sua própria existência. [...] a produção do homem é, ao mesmo tempo, a formação do homem, isto é, um processo educativo (SAVIANI, 2016, p. 19).

Parafraseando Saviani (2016, p.18), "quando vêm ao mundo, os membros da espécie humana já se encontram num contexto que é produto histórico, isto é, produto das ações das gerações precedentes". Nessa perspectiva, o autor considera que o papel da educação é tornar 
os indivíduos contemporâneos à sua época. Ao discutir as bases para uma concepção dialética de educação, pela qual o próprio passou, relata:

[...] a partir de 1984 a denominar de "pedagogia histórico-critica", afirmei que o movimento que via das observações empíricas ("o todo figurado na intuição") ao concreto ("uma rica totalidade de determinações e de relações numerosas") pela mediação do abstrato ("a análise, os conceitos e as determinações mais simples") constitui uma orientação segura tanto para o processo de descoberta de novos conhecimentos (o método científico) como para o processo de ensino (o método pedagógico). É a partir daí que podemos chegar a uma pedagogia concreta como via de superação tanto da pedagogia tradicional como da pedagogia moderna (SAVIANI, 2012, p. 78-79).

Desta maneira, as contribuições da pedagogia histórico-crítica para os alunos com ou sem deficiências residentes no campo estão amarradas nos pressupostos filosóficos discorridos na proposta pedagógico-metodológica e no significado político da sua realização. Isso porque, ao se fundamentar em bases marxistas, compreende-se a valorização da história, trabalho e conflitos humanos explicitados nos debates que tratam das políticas educacionais e, consequentemente, do homem que educa (SILVA, 2014). A pedagogia histórico-crítica com um olhar para interface entre as modalidades da educação do campo e educação especial, remete a uma escolarização que agrega os estudantes com deficiência residentes na zona rural. Neste sentido, Saviani (2016, p. 22) destaca que:

\begin{abstract}
A pedagogia histórico-crítica entende a educação como uma atividade mediadora no interior da prática social global. Como tal, o ponto de partida e o ponto de chegada da prática educativa é a prática social. Daí decorre um método pedagógico que parte da prática social onde professor e aluno se encontram igualmente inseridos ocupando, porém, posições distintas, condição para que travem uma relação fecunda na compreensão e encaminhamento da solução dos problemas postos pela prática social, cabendo aos momentos intermediários do método identificar as questões suscitadas pela prática social (problematização), dispor os instrumentos teóricos e práticos para a sua compreensão e solução (instrumentação) e viabilizar sua incorporação como elementos integrantes da própria vida dos alunos (catarse).
\end{abstract}

Ainda sobre as políticas educacionais que trazem em seu bojo a interface entre a educação do campo e educação especial, entende-se que exista uma demanda de estas serem assumidas e reivindicadas na perspectiva da pedagogia histórico-crítica, uma vez que tal teoria pedagógica é capaz de debater sobre estas políticas no intuito de possibilitar que professores, alunos e sociedade entendam a raiz dos problemas sociais e educacionais. Desta forma, se favorece a compreensão histórica "dos mecanismos explícitos e implícitos de exclusão educacional e social como elementos justificadores das desigualdades sociais, em especial da acumulação privada dos meios de produção e da exploração do homem pelo homem" (SILVA, 2014, 82).

Sob o olhar crítico da PHC, compreende-se haver nas políticas da educação do campo e educação especial a explicitação do direito do aluno com deficiência de ser escolarizado no campo, contudo, essa seguridade não garante a inclusão de todos nas salas regulares, ou ainda, no ensino complementar dado em contra turno nas Salas de Recursos Multifuncionais (SRM). Assim, deve-se estudar os aspectos históricos e sociais desta demanda escolar dos sujeitos do campo, afim de reivindicar seus direitos discorridos nos documentos. Ainda, evidencia-se no documento intitulado "Educação do Campo: marcos normativos", elaborado pelo Ministério da Educação, no âmbito da Secretaria de Educação Continuada, Alfabetização, Diversidade e Inclusão (SECADI), que: 


\begin{abstract}
A educação do campo, tratada como educação rural na legislação brasileira, tem um significado que incorpora os espaços da floresta, da pecuária, das minas e da agricultura, mas os ultrapassa ao acolher em si os espaços pesqueiros, caiçaras, ribeirinhos e extrativistas. $\mathrm{O}$ campo, nesse sentido, mais do que um perímetro nãourbano, é um campo de possibilidades que dinamizam a ligação dos seres humanos com a própria produção das condições de existência social e com as realizações da sociedade humana (BRASIL, 2012, p. 7-8).
\end{abstract}

Como já mencionava Germano (1993), a política educacional mostra-se como um dos aspectos de uma totalidade histórico-concreta, independente da formação social brasileira. Nesse sentido, se o desejo é compreender melhor sobre a quais interesses servia, ou por quem e como a educação era oferecida em cada um dos recortes temporais, é preciso fazê-la tomando o cuidado de observar determinados períodos.

Diante do exposto, é correto dizer que a educação oferecida aos trabalhadores do campo por longa data foi a chamada educação rural, caracterizada com um forte viés ideológico, o qual estabelecia que os saberes a serem ensinados eram aqueles de pouca utilidade, calcados na visão utilitarista da escola rural, com pouca ênfase em conteúdo. Tal forma de ensino intencionavase em manter a exploração dos trabalhadores por meio do trabalho manual, principalmente nas lavouras dos grandes latifúndios.

\title{
Os aspectos históricos da educação do campo brasileira
}

O termo ruralismo pedagógico foi cunhado para definir uma proposta de educação do trabalhador rural que tinha como fundamento básico a ideia de fixação do homem no campo por meio da pedagogia. Ou seja, um grupo de intelectuais, pedagogos ou livres-pensadores defendiam que deveria haver uma pedagogia que ajudasse a fixar o homem no campo, ou que, pelo menos, dificultasse, quando não impedisse, sua saída desse habitat, considerado natural para as populações que o habitaram ao longo de muito tempo (BEZERRA NETO, 2017, p.15).

Sob tal aspecto, o autor, ao discutir sobre o ruralismo pedagógico, destaca que tal proposta emerge num período histórico (década de 1930) em que o Brasil passava por importantes transformações no plano econômico e político ${ }^{6}$.

É preciso destacar que:

Em uma conjuntura marcada por mais uma crise cíclica do capitalismo, o início da década de 1930 foi caracterizado, no Brasil, por dificuldades econômicas e prejuízos para os proprietários de terras, produtores de gêneros agrícolas voltados à exportação e, em especial, para a oligarquia cafeeira, sofrendo consequentemente enfraquecimento político (BEZERRA NETO, 2017, p. 15).

Souza (2012) argumenta que para interpretar a evolução da educação no meio rural brasileiro, faz-se necessário retroceder a distintos recortes históricos, bem como, interpretar as influencias político-ideológicas que acabaram reforçando a dicotomia do território do grande produtor capitalista versus território do camponês, e do campo versus cidade.

\footnotetext{
${ }^{6}$ Para conhecer mais sobre o panorama da evolução econômica brasileira e o processo de desenvolvimento econômico brasileiro ao longo do Século XX, consulte a obra intitulada O Desenvolvimento Econômico Brasileiro de Argemiro J. Brum, publicada em 1994, pela editora Vozes.
} 
Em outras palavras, para a autora supracitada, o desinteresse para com a educação no meio rural por parte das lideranças brasileiras predominou até o momento em que a sociedade percebeu a necessidade da educação no meio rural.Conforme apresenta Leite (2002), este fato ocorreu como mecanismo de contenção do forte movimento migratório interno ocorrido entre os anos de 1910-1920, no qual um expressivo número de rurícolas deixa o campo e se desloca para áreas urbanas, iniciando um processo de industrialização.

Foi nesse contexto sócio-político e econômico que se desenvolveu o ruralismo pedagógico, ancorado na ideológica de fixação do homem no campo. Conforme aponta Bezerra Neto (2017, p. 18) os pedagogos ruralistas acreditavam ser relevante elaborar um currículo escolar "voltado a dar repostas às necessidades do homem no meio rural, visando atende-lo naquilo que era parte integrante do seu dia a dia".

Diante do exposto, reconhecendo as muitas carências apresentadas por esse modelo de educação desgastada e insuficiente para os povos do campo, a Educação do Campo origina-se, segundo Fernandes (2006), das demandas gestadas no interior dos movimentos camponeses pela construção da política de educação para áreas de reforma agrária.

Tomando de empréstimo as palavras de Caldart (2009, p. 35) a Educação do campo constitui-se como"um fenômeno recente da realidade educacional brasileira, que tem os movimentos sociais camponeses como principais protagonistas ". Assim, a gênese da Educação do campo tem origem com a "experiência de classe' de camponeses organizados em movimentos sociais e envolve diferentes sujeitos, às vezes com diferentes posições de classe" (CALDART, 2009, p. 38).

Nesse sentido, os avanços e conquistas alcançados para a elaboração e implementação de Políticas Públicas e Programas voltados ao atendimento da Educação do campo no Brasil, que também podem envolver pessoas com deficiência, são relativamente recentes. Além disso, pode-se dizer que estão intimamente associados às pressões provocadas pelos movimentos sociais ligados ao campo frente ao Estado, para fazer cumprir o direito social à educação e ao acesso ao conhecimento para trabalhar e produzir na terra.

No texto preparatório intitulado "Primeira Conferência Nacional - Por Uma Educação Básica do Campo", Fernandes, Cerioli e Caldart (2011, p. 22), destacam como objetivo de realização da Conferência, "ajudar a recolocar o rural, e a educação que a ele se vincula, na agenda política do país". No sentindo "de que é possível e necessário pensar/implementar um projeto de desenvolvimento para o Brasil, que inclua milhões de pessoas que vivem no campo, e de que a educação, além de um direito, faz parte desta estratégia de inclusão" (FERNANDES; CERIOLI; CALDART 2011, p. 22).

Sob tal perspectiva, os movimentos sociais do campo passam então a requisitar, por parte do poder público, uma educação específica e diferenciada para os povos que vivem e trabalham no campo, ancorada em uma concepção de "educação, no sentido amplo de processo de formação humana, que constrói referenciais culturais e políticas para a intervenção das pessoas e dos sujeitos sociais na realidade, visando a uma humanidade mais plena e feliz" (FERNANDES; CERIOLI; CALDART, 2011, p. 23).

Em outras palavras, solicitava-se uma educação básica do campo voltada aos interesses e ao desenvolvimento sociocultural e econômico das populações campesinas, considerando suas culturas e especificidades. Assim, haveria o direito de empoderar-se das políticas educacionais do campo, independente da condição social dos indivíduos.

O Estado precisa universalizar os direitos que vão se materializar por meio destas políticas e, diante disso, é preciso pensar que nesse segmento territorial também existem "pessoas com deficiência que também precisam ter os seus direitos garantidos, levando em consideração as particularidades e dificuldades que a condição territorial impõe ao seu desenvolvimento. Assim sendo, não podemos ter políticas generalistas" (PALMA, 2016, p. 36). 
Bezerra Neto e Bezerra (2011), ao argumentarem sobre o referencial teórico adotado pelo movimento denominado "Por Uma Educação do Campo", afirmam que tal referencial está "mais próximo de uma abordagem pós-moderna, com ênfase na cotidianidade e na subjetividade, considerando-o ineficaz para compreender e explicar a realidade dos trabalhadores do campo e a educação oferecida ao grupo a que esse movimento se refere" (BEZERRA NETO; BEZERRA, 2011, p. 15).

A posição teórico-metodológica dos autores supracitados aponta para o MHDe, nesse sentido, partindo de uma visão de totalidade, compreende a educação no campo como uma pequena parte constituinte de um projeto mais amplo de educação. Nessa perspectiva, a educação deve ser entendida numa relação dialética com a sociedade, sendo válido dizer que a educação por si só não mudará a sociedade, todavia, ela se coloca como elemento secundário e importante para o processo de transformação da sociedade.

Os movimentos sociais do campo têm papel fundamental no tensionamento do Estado pela formulação de políticas públicas voltadas à Educação do Campo que contemplem o direito do aluno com ou sem deficiência (BRASIL, 2008a), acrescentando que o Estado deveria assumir a responsabilidade de garantir escolas, profissionais, recursos e políticas educativas capazes de configurar a interface da Educação do Campo com a educação especial.

\section{O programa Sala de Recursos Multifuncionais nas escolas do campo}

Alguns programas têm sido criados pelo Ministério da Educação, sob a liderança do poder executivo e por meio da Diretoria de Políticas de Educação Especial (DPEE) e da atual SECADI. Essa secretaria surgiu por força do Decreto $n^{\circ} 7.690 / 12$, e menciona em seu Art. 20 que tem por objetivo:

\footnotetext{
I - planejar, orientar e coordenar, em articulação com os sistemas de ensino, a implementação de políticas para a alfabetização, a educação de jovens e adultos, a educação do campo, a educação escolar indígena, a educação em áreas remanescentes de quilombos, a educação em direitos humanos, a educação ambiental e a educação especial [...] III - coordenar ações transversais de educação continuada, alfabetização, diversidade, direitos humanos, educação inclusiva e educação ambiental, visando à efetivação de políticas públicas de que trata esta Secretaria, em todos os níveis, etapas e modalidades [...] (BRASIL, 2012, p.5).
}

Assim, por intermédio das políticas educacionais, o governo brasileiro criou programas com o intuito de facilitar a universalização do acesso à educação, oportunizando a entrada e a permanência de alunos com deficiência nas escolas regulares (rurais e urbanas). Sendo assim, tais programas devem perpassar a educação do campo, visto que neste também há alunos com deficiências.

Como exemplo destes programas, tem-se o Programa Escola Acessível, o Transporte Escolar Acessível, as Salas de Recursos Multifuncionais, entre outros. Dentre estes, considerase importante destacar neste estudo o programa Sala de Recursos Multifuncionais (SRM), sendo um dos mais relevantes para os estudantes com deficiência residentes nos ambientes rurais ou urbanos.

O programa SRM foi instituído pelo MEC/SECADI por meio da "portaria ministerial $n^{\circ}$ 13/2007, integra o Plano de Desenvolvimento da Educação (PDE) e Plano Nacional dos Direitos da Pessoa com Deficiência (PNDPD)" (BRASIL, 2010, p.9). Sua criação ocorreu com o intuito de complementar a escolarização dos alunos com deficiência, os quais devem, prioritariamente, estar matriculados nas escolas regulares de onde estão alocados (zona urbana 
ou rural). Na proposta, os alunos recebem, no contraturno da aula, o Atendimento Educacional Especializado (AEE) nas SRM.

Considerando que cabe à escola se organizar "para o atendimento aos estudantes com necessidades educacionais especiais, assegurando as condições necessárias para uma educação de qualidade para todos" (BRASIL, 2001, p. 01), a implantação das SRM nas escolas comuns da rede pública da zona rural e urbana de ensino deve atender à necessidade histórica da Educação nacional de promover as condições de acesso, participação e aprendizado dos estudantes com deficiência no ensino regular.

Desta forma, viabiliza-se a oferta do Atendimento Educacional Especializado "de forma complementar ou suplementar à escolarização" (BRASIL, 2010, p.03), sendo importante salientar que a Política Nacional de Educação Especial na Perspectiva da Educação Inclusiva menciona que:

\footnotetext{
$\mathrm{O}$ atendimento educacional especializado tem como função identificar, elaborar e organizar recursos pedagógicos e de acessibilidade que eliminem as barreiras para a plena participação dos estudantes, considerando suas necessidades específicas. A atividades desenvolvidas no atendimento educacional especializado diferenciam-se daquelas realizadas na sala de aula comum, não sendo substitutivas à escolarização. Esse atendimento complementa e/ou suplementa a formação dos estudantes com vistas à autonomia e independência na escola e fora dela (BRASIL, 2008b, p.11).
}

O AEE tem papel fundamental na atual proposta de inclusão de alunos com deficiência na escola regular, tendo por objetivo auxiliar o processo de inclusão escolar, visando não apenas o acesso dos estudantes, como também, sua permanência com qualidade dentro do sistema regular de ensino na zona rural ou urbana (JÚNIOR MELO; BARBOSA, 2016).

Palma (2016), a partir da reflexão sobre os dados obtidos em sua pesquisa, constatou que o AEE oferecido nas SRM nas escolas do campo é favorável em vários aspectos aos alunos com deficiência e seus professores. Quanto a esses benefícios, aponta as condições estruturais físicas de funcionamento e organização no âmbito escolar, além da percepção dos pais e professores acerca do trabalho a ser desenvolvido com os estudantes com deficiência.

A autora percebe as SRM nas escolas do campo como uma prática que aponta para um avanço em relação à garantia do direito à educação da população campesina que vive em assentamentos rurais, assim como, um meio que garante o direito de escolarização das pessoas com deficiência, da mesma forma com que é oferecido em escolas do meio urbano. Contudo identificou, impasses no AEE das escolas do campo, os quais também são percebidos no AEE das escolas da cidade, como por exemplo: a formação continuada de professores, o transporte para o AEE no contraturno, e o fato de haver uma única professora para atender três unidades escolares (PALMA, 2016).

Além das questões já discutidas sobre essas duas subáreas, cabe salientar que as políticas de Educação Especial (BRASIL, 2008b, 2011, 2015) têm o papel de combater a discriminação que ocorre pelo olhar de incapacidade para com as pessoas com deficiência, enquanto as políticas de Educação do Campo buscam combater a discriminação no meio rural, visto como um lugar de atraso e que não desfruta do desenvolvimento e da tecnologia. Desta forma, percebe-se haver objetivos em comum, "ressaltando que estas duas áreas sofrem pela produção social do preconceito" (PALMA, 2016, p. 22).

Machado e Vendramini (2013, p. 13) destacam que as políticas públicas ${ }^{7}$ são espaços de disputa, sendo necessário haver clareza sobre o que foi consenso entre os educadores e os

\footnotetext{
${ }^{7}$ De acordo com Gobert e Muller (1897) citado por Höfling (2001 p. 31),entende-se por Políticas Públicas o "Estado em ação", ou seja, é o Estado implantando um projeto de governo, por meio de programas e de ações voltadas a setores específicos da sociedade.
} 
movimentos sociais, assim como, saber quem dita as regras. Neste sentido, conforme alerta Santos e Bezerra Neto (2017, p. 19),

[...] o Estado, por meio de sua estrutura burocrático-administrativa e dos seus mecanismos de fiscalização e controle, historicamente, esteve (está) a serviço da classe dominante. Portanto, é necessária, a apreensão, do papel desempenhado pelas políticas públicas estatais, na medida em que ela procuram atender parcialmente às reivindicações dos movimentos sociais organizados, mas sem perder de vista a satisfação das demandas impostas pelo capitalismo.

Se em um panorama mais geral a garantia do direito social à educação para as populações que vivem e trabalham no campo tem sido objeto de controvérsias e disputas, acredita-se que as lacunas se ampliam quando considerada a manutenção do direito à educação no campo para os estudantes com deficiência, transtornos globais de desenvolvimento e altas habilidades ou superdotação.

O mesmo pode ser verificado no Artigo $2^{\circ}$ da Resolução do CNE/CEB N. 001/02, que institui as Diretrizes Operacionais para a Educação Básica nas Escolas do Campo:

Estas Diretrizes com base na legislação educacional, constituem um conjunto de princípios que visam adequar o projeto institucional das escolas do campo às Diretrizes Curriculares Nacionais para a Educação Infantil, o Ensino Fundamental e Médio, a Educação de Jovens e Adultos, a Educação Especial, a Educação Indígena, e a Educação Profissional de Nível Técnico e a Formação de Professores em Nível Médio na modalidade Normal (BRASIL, 2002, p. 07).

Assim, é notória a interface entre as duas modalidades nos dispositivos legais da educação. Contudo, Anjos (2016) aponta uma fragilidade encontrada na política educacional que envolve a Educação Especial e a Educação do Campo. Sobre isso, aponta que a educação campesina sofre frequentemente com o fechamento de escolas e dificuldades de transporte (quando este existe), o que faz com que alguns gestores públicos encaminhem o aluno com ou sem deficiência que mora no campo, para a cidade, de forma a livrar-se da responsabilidade local de cuidar destas escolas (ANJOS, 2016).

Além disso, de forma sutil, a LDB 9394/96 faz algumas inferências sobre a diversidade do campo brasileiro e suas peculiaridades. Os Artigos 23, 26 e 28 apontam algumas orientações para atender essa realidade, notadamente no que concerne à organização das escolas e das questões pedagógicas.

São previstos, quando necessários, serviços de apoio especializado para atender particularidades da educação especial, como o atendimento educacional em classes, escolas ou serviços especializados, sendo que, quando não possível em função das condições específicas do aluno, deve-se atendê-los em classes comuns do ensino regular. Ainda, prevê também que os sistemas de ensino assegurem, currículos, métodos, técnicas e recursos educativos, além de organização específica para o atendimento às necessidades dos alunos com deficiência, transtornos globais do desenvolvimento e altas habilidades ou superdotação (BRASIL, 1996).

Por sua vez, a Lei Brasileira de Inclusão da Pessoa com Deficiência (BRASIL, 2015), destina-se a assegurar e a promover, em condições de igualdade, o exercício dos direitos e das liberdades fundamentais pela pessoa com deficiência, visando sua inclusão social e cidadania, garante o direito a:

Acessibilidade como uma possibilidade e condição de alcance para utilização, com segurança e autonomia, de espaços, mobiliários, equipamentos urbanos, edificações, transportes, informação e comunicação, inclusive seus sistemas e tecnologias, bem como de outros serviços e instalações abertos ao público, de uso público ou privados 
de uso coletivo, tanto na zona urbana como na rural, por pessoa com deficiência ou com mobilidade reduzida (BRASIL, 2015, p.1).

Desta maneira, o Estatuto da Pessoa com Deficiência (EPD) remete para a importância da educação do Campo na vertente da escola especial, que considera o acesso ao conhecimento para todos, independentemente da origem, condição social, deficiência, gênero, raça e da localização espacial em que o indivíduo reside. O espaço do campo possui muitas especificidades, as quais a escola deve levar em consideração para que a escolarização de fato aconteça, proporcionando aos indivíduos campesinos o exercício prático do saber e a consequente transformação da realidade (PALMA, 2016).

É importante citar que o EPD (2015) menciona que a Educação se constitui como direito da pessoa com deficiência, e sua escolarização na escola comum (em área rural ou urbana) deve ser assegurada pelo sistema educacional brasileiro, sendo inclusivo em todos os níveis de aprendizado ao longo de toda a vida. Além disso, prevê o alcance do máximo desenvolvimento em relação aos seus talentos e habilidades, sejam estes físicos, sensoriais, intelectuais e sociais, fitando nos interesses e necessidades de aprendizagem desse estudante (BRASIL, 2015).

\section{CONSIDERAÇÕES FINAIS}

Por meio das informações e discussões trazidas neste trabalho, é possível constatar que as políticas públicas da educação do campo e da educação especial apresentam interface entre em favor dos estudantes com deficiência que residem no campo. Estas se consolidam por intermédio dos programas do governo federal, que visam o acesso e a permanência do PAEE no sistema educacional.

Contudo, existe um longo caminho a ser seguido para se alcançar uma educação de qualidade para os estudantes com deficiência. Hás questões pertinentes, como por exemplo, o transporte para a mobilidade destes alunos, que é um problema enfrentando na educação escolar oferecida na zona urbana e também na escolarização oferecida no campo.Outro ponto importante diz respeito à formação continuada dos professores para a realização do trabalho com os estudantes com deficiência, pois é preciso que estes tenham conhecimentos, habilidades e sensibilidade para observar e atender as peculiaridades de cada deficiência, favorecendo a escolarização destes alunos.

Cabe ressaltar também a criação e implementação do programa Sala de Recursos Multifuncionais, contudo, muito se tem a avançar para que sua adequada implementação, garantia e efetivação sejam alcançadas e disponibilizadas a todos, conforme preconizado nos documentos legais. Entretanto, é a permanência das reivindicações que auxiliam a mudança desta realidade.

Nesse sentido, questiona-se: bastaria garantir a matrícula e o acesso desses alunos com deficiência nas classes regulares? Em que condições se realizaria o atendimento desses alunos? $\mathrm{O}$ ambiente físico das escolas do campo é arquitetonicamente acessível para receber os alunos com deficiência? Estas são apenas algumas questões que provocam reflexões sobre o distanciamento existente entre as orientações legais e a efetivação prática daquilo que deveria ser direito de todos os cidadãos brasileiros.

As políticas públicas, no que tange aos decretos, leis e outros dispositivos legais analisados, são ferramentas importantes para incluir e auxiliar na solução dos reais problemas enfrentados na efetivação da inclusão da pessoa com deficiência no ambiente de ensino regular no campo. Entretanto, é preciso que os olhares contemplem uma cultura educacional inclusiva que valorize mais as peculiaridades das pessoas com deficiência que residem no campo. 
Contudo considerar os aspectos culturais não significa isolar as comunidades do campo em nome de uma falsa valorização dos saberes tradicionais e populares, pois esses conhecimentos somente serão estimados à luz da pedagogia histórico-crítica se os conhecimentos historicamente acumulados pela sociedade forem transmitidos para todos os cidadãos, sejam estes residentes no campo ou na cidade, com ou sem deficiência.

Assim, acredita-se que existe a necessidade de um melhor acompanhamento dos programas instituídos pelo mistério da educação por meio das políticas públicas educacionais. Deve-se buscar soluções para os problemas já apresentados por algumas pesquisas, assim como, novas alternativas interventivas nos próprios programas existentes, para que as políticas saiam do papel e se tornem prática no cotidiano escolar de fato.

\section{REFERÊNCIAS}

ANJOS, C. F. Realidades em contato: construindo uma interface entre a educação especial e a educação do campo. 2016.231f. Dissertação (Mestrado em Educação), Programa de Pósgraduação em Educação, Universidade Federal do Espírito Santo, Vitória, 2016.

BEZERRA NETO, L.; BEZERRA, M. C. dos S. Educação do Campo: referenciais teóricos em discussão. In: BEZERRA NETO, L.; BEZERRA, M. C. dos S. (Orgs.). Educação do Campo em discussão: subsídios para o Programa Escola Ativa. São José: Premier, 2011. p.101-120

BEZERRA NETO, L.; BEZERRA, M. C. dos S.; CAIADO, K. R. M. Escola Ativa: Qual a sua contribuição para a educação do trabalhador do campo?In: BEZERRA NETO, L.; BEZERRA, M. C. dos S. (Orgs.). Educação do Campo em discussão: subsídios para o Programa Escola Ativa. São José: Premier, 2011. p.9-19.

BEZERRA, M. C.S.; SANTOS, F. R. dos. Educação no campo: elaborações teóricas e práticas. In: SANTOS NETO, J. L. dos; BEZERRA NETO, L.; BEZERRA, M.C. dos S. (Orgs.). Trabalho e educação: estudos sobre o rural brasileiro. São Carlos: Pedro \& João Editores, 2017. p. $15-37$

BEZERRA NETO, L.Educação Rural no Brasil: do ruralismo pedagógico ao movimento por uma educação do campo. São Carlos: Pedro \& João Editores, 2017.

BRASIL. Constituição. Constituição da República Federativa do Brasil. Brasília, DF: Senado Federal, 1988.

Ministério da Educação. Lei de Diretrizes e Bases da Educação Nacional - LDB no 9.394, de 20 de dezembro de 1996. 
BRASIL. Resolução CNE/CEB no 2/2001. Institui Diretrizes Nacionais para a Educação Especial para a Educação Básica. Brasília, 2001.

Resolução CNE/CEB n ${ }^{0}$ 2/2008b. Estabelece diretrizes complementares, normas $e$ princípios para o desenvolvimento de políticas públicas de atendimento da Educação Básica do Campo. Brasília, 2008a.

BRASIL. Política Nacional de Educação Especial na Perspectiva da educação Inclusiva. Brasília, MEC/SEESP, 2008b.

BRASIL. Decreto $n^{o} 7.352$, de 4 novembro de 2010. Dispõe sobre a política de educação do campo e o Programa Nacional de Educação na Reforma Agrária-PRONERA. 2010.

Decreto $n^{\circ} 7.611$, de 17 de novembro de 2011. Dispõe sobre a educação especial, o atendimento educacional especializado e dá outras providências. 2011.

BRASIL. Educação do Campo: marcos normativos. Brasília: MEC/SECADI, 2012.

BRASIL. Lei $n^{o}$ 13.146, de 6 de julho de 2015. Institui a Lei Brasileira de inclusão da Pessoa com Deficiência (Estatuto da Pessoa com Deficiência), Brasileira, 2015.

BRASIL. Ministério da Educação. Lei de Diretrizes e Bases da Educação Nacional - LDB no 9.394, de 20 de dezembro de 1996. Edição atualizada, 2017.

CAIADO, K. R. M.; MELETTI, S. M. F. Educação especial na educação do campo: 20 anos de silêncio no GT 15. Rev. Bras. Ed. Esp., Marília, v.17, p. 93-104, maio/ago. 2011.

CALDART, R. S. Educação do Campo: Notas para uma análise de percurso. Trab. Educ. Saúde, Rio de Janeiro, v. 7 n. 1, p. 35-64, mar./jun. 2009.

FERNANDES, B. M. Os campos da pesquisa em Educação do Campo: espaço e território como categorias essenciais. In: MOLINA, M. C. Educação do Campo e Pesquisa: questões para reflexão. Brasília/MDA, 2006. p. 27-98.

FERNANDES, B. M.; CERIOLI, P. R.; CALDART, R. S. Primeira Conferência Nacional "Por Uma Educação Básica do Campo (Texto Preparatório). In: ARROYO, M.; CALDART, R. S.; MOLINA, M. C. (Orgs.). Por Uma Educação do Campo. 5. Ed. Petrópolis: Vozes, 2011. p. 20 62. 
GERMANO, J. W. Estado Militar e Educação no Brasil (1964-1985). São Paulo: Cortez, 1993.

GOMES, M. A.; COLARES, M. L. I. S. Educação em tempos de neoliberalismo: dilemas e possibilidades. Acta Scientiarum. v. 34, n. 2, p. 281-290, jul./dez. 2012.

GONÇALVES, T. G. G. L. Alunos com deficiência na Educação de Jovens e Adultos em assentamentos paulistas: Experiências do PRONERA 2014. Tese (Doutorado em Educação Especial) - Programa de Pós-graduação em Educação Especial, Universidade Federal de São Carlos, São Paulo, 2014.

HÖFLIN, E. de M. Estado e Políticas (públicas) sociais. Cadernos CEDES, Ano XXI, n. 55, p. 30-41, nov. 2001.

JESUS, D. M.; ANJOS, C. Tecendo interfaces entre a educação especial e educação do campo: O cenário do Espírito Santo. In: I XVI ENDIPE - Encontro Nacional de Didática e Práticas de Ensino - UNICAMP - Campinas - 2012. Didática e práticas de ensino na realidade escolar contemporânea [recurso eletrônico]: constatações, análises e proposições. Araraquara: Junqueira \& Marin, 2012. Disponível em: <http://www.infoteca.inf.br/endipe/smarty/templates/arquivos_template/upload_arquivos/acer vo/docs/1931c.pdf>. Acesso em ago. 2018.

JUNIOR MELO, A. L.; BARBOSA, M. O. Políticas públicas educacionais: um olhar sobre as salas de recursos multifuncionais. In: VII Congresso Brasileiro de Educação Especial (CBEE) $e$ do X Encontro Nacional de Pesquisadores da Educação Especial (X ENPEE), 2016, São Carlos-SP: ABPEE, 2016. v. 7. p. 1-15.

LEITE, S. C. Escola rural: urbanização e políticas educacionais. São Paulo: Cortes, 2002.

LOUREIRO, A. D. T.; SÁ, M. A.; SELINGARDI, S. A. Interface da educação especial com a educação do campo: análise do censo escolar de quatro municípios paulistas. In: Seminário de estudos e pesquisa sobre educação do campo, 2011. São Carlos. Disponível em: <http://www.semgepec.ufscar.br/trabalhos/eixo-8/aline-dozzi-teza>. Acesso em: 12 fevereiro de 2012.

LOMBARDI, J. C. Algumas questões sobre educação e ensino em Marx e Engel. Revista HISTEDBR On-line, Campinas, v 1. n. especial, p. 347-366, abr. 2011

MACHADO, I. F.; VENDRAMINI, C. R. Políticas Públicas para a Educação do Campo: das necessidades aos limites. Revista Ibero-Americana de Estudos em Educação., v. 8, n. 1, 2013. P. 
<https://periodicos.fclar.unesp.br/iberoamericana/article/view/66470/4779>. Acesso em: ago. 2018.

ORSO, P. J. Pedagogia Histórico-Crítica no campo. In: BASSO, J. D.; SANTOS NETO, J. L. dos; BEZERRA, M.C. dos S. (Orgs.). Pedagogia Histórico-Crítica e Educação no Campo História, Desafios e Perspectivas Atuais. São Carlos: Pedro \& João Editores, 2016. p. 93-115.

PALMA, D. T. Escolas do campo e o atendimento educacional especializado em sala de recursos multifuncional. 2016. 142 f. Dissertação (Mestrado em educação escolar) - Programa de Pós-Graduação em Educação, Universidade Estadual Paulista Júlio de Mesquita Filho, Araraquara, 2016.

PASTORIZA, T. B. Ensino de Geografia para alunos com cegueira no Ensino Fundamental I: contribuições da Pedagogia Histórica-Crítica. 2015.127 f. Dissertação (Mestrado em Educação) - Programa de Pós-Graduação em Educação, Universidade Federal de São Carlos, 2015.

SANTOS, F. R.; BEZERRA NETO, L. Movimentos sociais e políticas públicas de educação para as populações que habitam no meio rural. Impulso, Piracicaba v. 27, n. 70, p. 17-32, set./dez. 2017. Disponível em: <https://www.metodista.br/revistas/revistasunimep/index.php/impulso/article/view/3365/2015>. Acesso em: 12 jun. 2018.

SAVIANI, D. Marxismo, Educação e Pedagogia. In: SAVIANI, D.; DUARTE, N. (Orgs.). Pedagogia histórico-crítica e luta de classe na educação escolar.Campinas: Autores Associados, 2012. p. 59-85.(Coleção polêmicas do nosso tempo).

SAVIANI, D. História das ideias pedagógicas no Brasil. Campinas: Autores Associados, 2013.

SAVIANI, D. A Pedagogia Histórico-Crítica na Educação do Campo. In: BASSO, J. D.; SANTOS NETO, J. L. dos; BEZERRA, M.C. dos S. (Orgs.). Pedagogia Histórico-Crítica e Educação no Campo - História, Desafios e Perspectivas Atuais. São Carlos: Pedro \& João Editores, 2016. p. 17-44.

SEVERINO, A. J. Metodologia do trabalho científico. São Paulo: Cortez, 2011.

SILVA, R. H. R. Contribuições da pedagogia histórico-crítica para a educação especial brasileira. Revista HISTEDBR On-line, Campinas, n. 58, p. 78-89, set 2014.

SOUZA, F.E. de. As "geografias" das escolas no campo do município de Goiás: instrumento para a valorização do território do camponês? 2012. 380 f. Tese (Doutorado em Geografia) - 
Programa de Pós-Graduação em Geografia, Universidade Estadual Paulista, Presidente Prudente, 2012.

Recebido em: 10/01/2018

Aceito em: 28/02/2018 